\title{
A água como destino: Na Colônia de Pescadores Z-3, territórios e territorialidades entre mar e terra
}

\author{
Water as destination: In the Z-3 Fishermen's Colony, territories \\ and territorialities between sea and land
}

Enviado em: 14/01/2018

Aceito em: 14/01/2018

RIBEIRO, Angelita Soares ${ }^{1}$

ROSA, Rogério Reus Gonçalves da² BUSSOLETTI, Denise Marcos ${ }^{3}$

HAERTER, Leandro ${ }^{4}$

\begin{abstract}
Resumo:
Nesse texto refletimos sobre os modos de (des/re)territorialização vivenciados pelos pescadores e pescadoras da Colônia de Z-3, situada na costa sul da Lagoa dos Patos, município de Pelotas, Rio Grande do Sul, Brasil. Para isso realizamos aproximações entre os campos da geografia e da antropologia buscando abordar os processos inerentes a territorialidades resilientes que emergem mantendo o vínculo dessas pessoas com a pesca artesanal e o espaço costeiro no qual se inserem. Com base no campo teórico citado e a partir de etnografias realizadas entre os anos de 2010 e 2012, e 2017 , compreendemos que as ideologias territoriais dos habitantes da Colônia de Pescadores Z-3 se elaboram em consonância à formulação de uma cosmologia costeira que, do simbólico ao mítico, irá atravessar a vida cotidiana nesse território limiar entre mar e terra.
\end{abstract}

\footnotetext{
1 Doutoranda no Programa de Pós-Graduação em Educação da Universidade Federal de Pelotas (PPGE/UFPel), pesquisadora no Grupo Interdisciplinar de Pesquisa: Narrativas, Arte, Linguagem e Subjetividade (GipNals) e Coordenadora do Núcleo de Extensão e Pesquisa em Educação, Memória e Cultura (NEPEC). Assistente Social no Campus Pelotas Visconde da Graça (CaVG) do Instituto Federal de Educação, Ciência e Tecnologia Sul-rio-grandense (IFSul). E-mail: angelitaribeiro@cavg.ifsul.edu.br

2 Doutor em Antropologia Social pela Universidade do Rio Grande do Sul (UFRGS), coordenador do Núcleo de Etnologia Ameríndia (NETA). Etnólogo e professor do Bacharelado em Antropologia e do Programa de Pós-Graduação em Antropologia (PPGAnt), da UFPel. E-mail: rosa.rogeriogoncalves@uol.com.br

3 Doutora em Psicologia pela Pontifícia Universidade Católica do Rio Grande do Sul (PUCRS), coordenadora do GipNals. Professora Associada na UFPel. E-mail: denisebussoletti@gmail.com

${ }^{4}$ Doutorando no PPGE/UFPel e pesquisador no GipNals. Técnico em Assuntos Educacionais no Campus Pelotas do IFSul,. E-mail: leandro@pelotas.ifsul.edu.br
} 
Palavras-Chave: Mitologia costeira, pesca artesanal, resiliência

\begin{abstract}
:
In this text we reflect on the modes of territorialization, deterritorialization and reterritorialization experienced by the fishermen and fisherwomen of the Colônia Z-3, located on the southern coast of Lagoa dos Patos, in the municipality of Pelotas, Rio Grande do Sul, Brazil. To do this, we make approximations between the fields of geography and anthropology, seeking to approach the processes inherent to resilient territorialities that emerge, maintaining the bond that these people have with artisanal fishing and the coastal space in which they are inserted. Based on the aforementioned theoretical field and from ethnographies carried out between the years 2010, 2011, 2012 and 2017, we understand that the territorial ideologies of the inhabitants of the Z-3 Fishermen's Colony are elaborated in consonance with the formulation of a coastal cosmology that, from the symbolic to the mythical, intersects daily life in this territory between sea and land.

Keywords: Coastal Mythology, artisanal fishing, resilience
\end{abstract}

\title{
Introdução
}

O presente texto aborda a dimensão do território e da territorialidade na Colônia de Pescadores Z-3, na costa sul da Lagoa dos Patos, na cidade de Pelotas, Rio Grande do Sul, a partir de etnografias realizadas entre os anos de 2010 e 2012, e 2017.

Parte do campo conceitual da geografia, procurando promover um diálogo com a antropologia e, assim, formular um fio teórico-metodológico que possibilitará a problematização das questões que se colocam a partir do campo etnográfico. A partir de dados de diários de campo, observações participantes e entrevistas realizadas com pescadores e pescadoras da Z-3, buscamos abordar os processos inerentes a territorialidades resilientes que emergem mantendo o vínculo dessas pessoas com a pesca artesanal e o espaço costeiro no qual se inserem.

Compreendemos que as ideologias territoriais dos habitantes da Colônia de Pescadores Z-3 se elaboram em consonância à formulação de uma cosmologia costeira que, do simbólico ao mítico, irá atravessar a vida cotidiana nesse território limiar entre mar e terra. 


\title{
1. Território e Territorialidade
}

\begin{abstract}
Para a ciência geográfica território é um conceito central. É interpretado de diferentes maneiras por alguns autores e correntes geográficas, cada um abordando diferentes aspectos do território, alguns o entendendo numa escala maior, de território nacional, outros na escala do local/lugar, porém, em comum o reconhecimento da existência de múltiplos territórios e territorialidades. (RIBEIRO, 2009, p. 50).
\end{abstract}

Nesse primeiro capítulo serão tratadas algumas discussões que a geografia tem promovido acerca da concepção de território e de territorialidade. Buscamos entre tantas abordagens, um arranjo de concepções que nos auxilie na compreensão daquilo que tem se colocado a partir de experiências etnográficas realizadas na Colônia de Pescadores Z-3.

\subsection{Em aproximação com a geografia, em busca do conceito de território}

Para Friedrich Ratzel (1990), o território define-se como uma determinada porção da superfície terrestre apropriada por um grupo humano. Com formação naturalista, o autor vincula o conceito de território à concepção de hábitat, sendo o território por isso, sinônimo de solo, meio ambiente, água, clima e palco necessário para a efetivação da vida humana. Ratzel ainda defende que a apropriação territorial de um coletivo social é condição sine qua non para que o mesmo possa alcançar suas reivindicações políticas.

Para Claude Raffestin (1993, p. 23) "[...] três sinais são mobilizados para caracterizar o Estado: a população, o território e a autoridade. Toda a geografia do Estado deriva dessa tríade". Para o autor, o poder - que se coloca como parte intrínseca de toda relação - visa o controle sobre os homens e as coisas, sendo a população, o território e os recursos, os trunfos de tal poder. Ao mesmo tempo, propõe uma análise sobre a relação das populações com o poder, sendo elas ao mesmo tempo, um trunfo, um recurso e um fundamento, e fonte de todos os atores sociais no jogo relacional. O recenseamento, por exemplo, se coloca como um dos aparelhos de saber e controle que o Estado opera sobre a população em seus territórios. Entretanto, essa mesma população é também um ator-trunfo com poder de reação e resistência às tentativas de desterritorialização forçada. 
Para Marcelo Lopes de Souza (2009), o que define o território é o poder. Ainda que não desconsidere a dimensão cultural e econômica, afirma que é a dimensão política que define o perfil do território. Criticado por negligenciar a dimensão cultural do território, defende-se argumentando que a separação que até então se fez entre o político, o cultural e o econômico tem se dado de maneira reducionista. Sobre isso Souza (2009) defende que:

\footnotetext{
Em cada caso concreto, ao se examinarem os fatores por trás de processos de territorialização, descobriremos, recuando no tempo e escavando o suficiente, um emaranhado de razões e motivações. A defesa de uma identidade pode estar associada a uma disputa por recursos e riquezas, no presente e no passado; a cobiça material não é, de sua parte, descolável do simbolismo, da cultura. (SOUZA, 2009, p. 60).
}

Para o autor, quando falamos em processos de (des)territorialização, estamos falando de algo que é "sempre, e em primeiro lugar, um processo que envolve o exercício de relações de poder e a projeção dessas relações no espaço", apesar de defender que "nenhuma dimensão é por conta dessa compreensão, excluída ou negligenciada." (SOUZA, 2009, p. 60).

Por outro lado, Rogério Haesbaert propõe uma abordagem do conceito de território em uma perspectiva que congrega as dimensões econômica, política e cultural. Nesse sentido, "[...] o território carregaria sempre, de forma indissociável, uma dimensão simbólica ou cultural em sentido estrito, e uma dimensão material, de natureza predominantemente econômico - política" (HAESBAERT, 2004, p. 112).

Pensando o território cultural, Haesbaert (2007) afirma ter crescido nos últimos tempos o diálogo entre perspectivas territoriais da geografia e da antropologia. Este encontro entre a geografia e a antropologia permite que o território seja compreendido em uma ordem que vincula o visível e o invisível, o imanente e o transcendente, o histórico e o mítico, o sociológico e o cosmológico. Citando Godelier o autor explica:

\footnotetext{
[...] o que reivindica uma sociedade ao se apropriar de um território é o acesso, o controle e o uso, tanto das realidades visíveis quanto dos poderes invisíveis que os compõem, e que parecem partilhar o domínio das condições de reprodução da vida dos homens, tanto a deles própria quanto a dos recursos dos quais eles dependem. (GODELIER, 1984, apud HAESBAERT, 2007, p. 39)
}

$\mathrm{Na}$ mesma perspectiva, os geógrafos Bonnemaison e Cambrèzy (apud Haesbaert, 2007), afirmam que sobrevive uma lógica culturalista de base identitária, 
que se impõe sob uma lógica funcional e estatal moderna. Em vista disso, os autores defendem que o território é antes de tudo um valor que se elabora em uma relação espiritual com os espaços de vida. O território cultural, em perspectiva radical, precederia assim os territórios político e econômico. Haesbaert, (2007, p. 24), explica que Bonnemaison

\footnotetext{
[...] inspirou-se em sua tese na sociedade da ilha de Tanna, no arquipélago de Vanuatu, bem pouco "pós-moderna", onde o território ("cultural") não é um produto dessa sociedade, mas uma entidade que a precede e a funda, os habitantes locais auto-definidos como man-ples, "homens lugares". [...] Segundo o próprio Bonnemaison, os habitantes de Tuva não "possuem" o território, mas se identificam com ele.
}

Esses "homens lugares" antes de possuírem o domínio político de seu território são parte do mesmo. Os conflitos territoriais (pelos processos de desterritorialização forçada) e os modos de viver se misturam com as narrativas míticas sobre a criação daquele povo. O vínculo com o território no caso dos man-ples não se demarca a partir de limites geopolíticos, antes se alicerça em uma legitimidade simbólica e mítica. Estamos assim falando de uma ideologia territorialista resiliente, ainda na ausência do acesso político a um território, ou, em outros termos, de uma territorialidade resiliente mesmo em processos de desterritorialização.

Para Haesbaert (2007), embora em contextos distintos aos das sociedades tradicionais, teríamos em nosso atual tempo globalizado um certo retorno às "ideologias territoriais", onde os processos de reafirmação simbólica de territorialidades impõem-se como argumento para a (re)apropriação efetiva do território político.

\title{
1.2 Em busca do conceito de territorialidade
}

\begin{abstract}
A territorialidade, além de incorporar uma dimensão estritamente política, diz respeito também às relações econômicas e culturais, pois está intimamente ligada ao modo como as pessoas utilizam a terra, como elas próprias se organizam no espaço e como elas dão significado ao lugar (HAESBAERT, 2004, p. 21).
\end{abstract}

Haesbaert e Limonad (2007) elaboraram um estudo introdutório acerca das territorialidades emergentes no séc. XXI, pautados no seguinte questionamento: Essas territorialidades são novas ou não? Os autores irão concluir que no decorrer do século XX se consolida uma identidade entre Estado (poder) e espaço (tornado território), 
construindo-se assim uma unidade territorial pautada em uma concepção político administrativa. Diante disso, múltiplas e distintas identidades territoriais foram abafadas em nome de uma identidade nacional homogênea.

Ao mesmo tempo, "[...] muitas destas territorialidades, imersas sob o jugo da construção identitária padrão dos Estados-nações, ressurgem e provocam uma redefinição (ou mesmo indefinição) de limites político-territoriais, alterando a face geográfica do mundo neste fim de milênio" (HAESBAERT; LIMONAD, 2007, p. 10).

Simultâneo a esse processo, pode-se perceber hoje, certo retorno das "ideologias-territoriais", já referidas no capítulo anterior, que em pleno mundo globalizado, manifestam territorialidades simbólicas que se impõe como argumento de defesa do controle e acesso ao território.

Trata-se de uma territorialidade que existe mesmo sem um território fisicamente estabelecido ou garantido, como em uma situação de apropriação territorial simbólica que emerge como argumento nas lutas por direitos territoriais. Podemos aí citar lutas em defesa de territórios que se elaboram a partir do conjunto de mitos elaborados por um grupo. Este é o caso do Waiãpi da Amazônia que defendem o território da Fortaleza de Macapá como um território indígena que foi construído pelo herói mítico lanejar para abrigar a verdadeira humanidade, Waiãpi $i^{5}$. Estamos falando de uma apropriação simbólica sobre um determinado território, em tensionamento a uma apropriação do poder político necessário ao acesso e ao controle territorial. Lamentavelmente as duas formas de apropriação nem sempre caminham lado a lado.

No que diz respeito aos pescadores artesanais, Gianpaolo Adomilli (2002) apresenta um estudo antropológico sobre o cotidiano de trabalho, a construção da identidade social e o viver dos pescadores do Parque Nacional da Lagoa do Peixe. O recorte realizado se dá sob as relações de conflito entre pescadores e instituições públicas de fiscalização e gestão ambiental, em destaque o IBAMA. A partir do decreto lei 93.546 de 1986, o lugar onde habitam esses pescadores torna-se Parque Nacional, portanto, área de preservação ecológica, gerando uma série de impasses no que tange a relação natureza/cultura.

A partir das contribuições de autores como Antonio Carlos Diegues (2000), Adomilli (2002) faz uma crítica ao modelo de Parque Nacional importado dos Estados Unidos a partir da década de 1970, onde se entende que a preservação ambiental

\footnotetext{
${ }^{5}$ Ver GALLOIS, 1994.
} 
pressupõe a ausência da ação humana. O esforço teórico e empírico de Adomilli (2002) é o de resgatar as práticas socioculturais dos pescadores frente a um processo que tende à sua exclusão social, negando-Ihes o território e com isso sua identidade social, cultural e política.

A exclusão territorial que ocorre no Parque Nacional Lagoa do Peixe nega as territorialidades ali formuladas, evidenciadas nas práticas sócio -econômico -culturais do coletivo costeiro que há décadas habita aquele território. Neste contexto, Diegues (1996) argumenta:

\begin{abstract}
Vários parques e reservas ecológicas no litoral brasileiro foram criados sem consulta aos pescadores que vivem do uso de seus recursos naturais. $\mathrm{Na}$ verdade, se eles estavam preservados era precisamente pelo respeito que os pescadores artesanais têm pelos mesmos, dos quais dependem para viver. A criação dessas unidades de conservação tem levado sistematicamente à proibição das atividades pesqueiras e até a expulsão desses pequenos produtores de suas praias. Por outro lado, a fiscalização rigorosa sempre incide sobre o pescador artesanal, autuando menos a pesca industrial, os barcos de arrasto, as serrarias e madeireiras, as empresas de palmito, etc. (DIEGUES, 1996, p. 133-134)
\end{abstract}

Nesse contexto, com base nos autores aqui citados e nos dados obtidos em campo etnográfico, entendemos que os processos de desterritorialização aos quais são submetidos os pescadores e as pescadoras artesanais, englobam o controle de seu acesso ao território da pesca pelos órgãos governamentais de regulação ambiental. Ou seja, mesmo vivendo em territórios que não se configuram enquanto áreas de preservação, tais coletivos sofrem anualmente as conseqüências da normativas legais que não contemplam seus conhecimentos e vínculos tradicionais com o mar ${ }^{6}$.

Agregamos a nosso argumento, a teoria que Gustavo Moura elabora (2017)baseado nas contribuições de Michel Foucault, Michel de Certeau, Claude Rafestin, Rogério Haesbaert e Boaventura de Sousa Santos-, acerca dos processos de territorialização estratégica, colocados a partir de modalidades de governamentalização do Estado Moderno fundadas em uma perspectiva epistemológica colonial.

Na perspectiva do território enquanto conhecimento, a emergência do Estado Moderno também vai gerar um processo de des-re-territorialização das sociedades tradicionais primeiramente na Europa e, com a expansão do colonialismo cultural, em outras partes do mundo. Neste processo, uma produção moderna do espaço significa a expropriação e a apropriação de espaços de produção do conhecimento destruindo os modos e os meios de produção dos espaços tradicionais (CET) que são substituídos por um modo

\footnotetext{
${ }^{6}$ Ou rios, lagoas, etc., dependendo da região do país.
} 
e meio de produção do espaço epistêmico moderno, a racionalidade científica ocidental, o que gera em nível planetário uma monocultura mental (MOURA, 2017, p. 48).

Tal racionalidade (pós)colonial moderna, surda às epistemologias tradicionais costeiras, irá se manifestar em duas formas de Estado no território da pesca: Um Estado regulatório para a pesca artesanal e um Estado de base econômica (neo)liberal para a pesca industrial.

Bernardo Mançano Fernandes (2008) diz que ao prevalecer as abordagens territoriais numa acepção de território quase sempre como espaço de governança, perdem-se as conflitualidades dos diferentes tipos de território e com isso sua multiescalaridade. Considerar tais conflitos significaria reconhecer os territórios das diferentes classes sociais e, sua multidimensionalidade, uma vez que, reconhecê-la, implicaria consequentemente na socialização das tomadas de decisão. É nesse contexto que, para o autor, o conceito de território é usado como instrumento de controle social onde, acreditamos, territorialidades precisam ser deslegitimadas através de seu condicionamento ao controle político e econômico do território.

Assim, para Fernandes (2008), considerar o território como uno, ou seja, apenas como espaço de governança e ausente da ideia dos outros territórios presentes, é reduzir este conceito a um instrumento de dominação por meio de políticas neoliberais. "Nesta condição, uma determinada região é escolhida para a aplicação de políticas de desenvolvimento, em grande parte, a partir dos interesses do capital." (p. 280).

Tratar o território da pesca, como uno é negligenciar a existência de dois territórios distintos em conflito permanente, pois enquanto a pesca industrial pauta-se na produção da mercadoria e acumulação do capital, a pesca artesanal pauta-se em epistemologias tradicionais, vínculos simbólicos e materiais, e na preservação de um lugar de subsistência e vida do qual as comunidades costeiras são parte.

Neste contexto, cada território da pesca vai configurar uma territorialidade distinta. Enquanto para a pesca industrial de grande aparato tecnológico e econômico, a presença humana não é central e, por isso, torna-se extremamente complexo pensarmos que tipo de territorialidade poderia manifesta-se ali $^{7}$, na pesca artesanal o

\footnotetext{
7 Não excluímos aqui a dimensão dos trabalhadores de grandes embarcações industriais, e a forma como o trabalho intensivo e por vezes de grande duração em mar aberto, provavelmente produza formas de territorialidade e vínculo com o território aquático. No entanto, as etnografias realizadas não dão conta de tal universo, e sim dos coletivos que vivem da pesca artesanal, compreendendo que para esses o
} 
mar, em seus ciclos de vida, vai determinar o ritmo cotidiano nas comunidades costeiras. Na pesca artesanal os limites entre trabalho e vida tornam-se bastante tênues. Sobre isso, conclui Adomilli (2002, p. 44):

Os aspectos que definem o ritmo da vida social são os ritmos da pesca. Os deslocamentos, de acordo com os ciclos e os períodos de escassez e fartura na pesca, envolvem toda a relação de socialização entre os pescadores, transformando o 'ritmo ecológico' em 'ritmo social' anual' .

No próximo tópico nos detemos aos ritmos da pesca ecoados da vida social e comunitária da Colônia Z-3. Tais ritmos entre terra e mar irão configurar territorialidades que, na tensão entre os processos de (des/re)territorialização do pescador artesanal e a sobrevivência de suas identidades territoriais, elaboram-se como forma de resiliência em um contexto de sobrevivência cada vez mais adverso.

\title{
2. Território e Territorialidade na Colônia de Pecadores Z-3
}

Acerca do território político-administrativo da Colônia Z-3, cabe dizer que a comunidade localiza-se no $2^{\circ}$ distrito do município de Pelotas, e, de acordo com o artigo $2^{\circ}$, inciso II, da lei municipal 5.490 de 2008, limita-se da seguinte forma:

\begin{abstract}
Ao norte: inicia no encontro da BR-116 com o Arroio Corrientes, seguindo por este, águas abaixo, até a Lagoa Pequena, seguindo, no sentido oeste/leste, pela margem norte da Lagoa Pequena, até encontrar o Canal da Feitoria, seguindo por este, no sentido oeste/leste, até encontrar a Lagoa dos Patos. Ao leste: inicia no encontro do Canal da Feitoria com a Lagoa dos Patos, seguindo pela margem da Lagoa dos Patos até 500,00 metros aquém do prolongamento da Avenida Alagoas, no Balneário dos Prazeres. Ao sul: inicia no encontro de uma linha paralela afastada 500,00 metros a nordeste da Avenida Alagoas com a Lagoa dos Patos, seguindo, no sentido sudeste/noroeste, por esta linha até 500,00 metros além da Avenida Adolfo Fetter, seguindo, no sentido nordeste/sudoeste e depois no sentido leste/oeste, por uma linha paralela afastada 500,00 metros da Avenida Adolfo Fetter, até encontrar o Arroio Pelotas, seguindo por este, águas acima, até um ponto situado 500,00 metros além do prolongamento da Avenida Alfredo Theodoro Born, seguindo, no sentido sudeste/noroeste, por uma linha paralela afastada 500,00 metros da Avenida Alfredo Theodoro Born, até encontrar uma linha paralela afastada 500,00 metros do Corredor Quatro da Avenida Ildefonso Simões Lopes, seguindo, no sentido sudeste/noroeste, por esta linha, até um ponto 500,00 metros além do prolongamento da Avenida Zeferino Costa, seguindo, no sentido nordeste/sudoeste, por uma linha paralela afastada 500,00 metros do prolongamento da Av. Zeferino Costa, até
\end{abstract}

trabalho na pesca dita cotidianamente os ritmos e vínculos no mar e na terra. Cabe ainda salientar que a crítica realizada à pesca industrial obviamente não se dirige aos trabalhadores desta atividade, mas ao grande mercado e às políticas governamentais que sustentam tal sistema ao preço de um ataque exterminatório às comunidades tradicionais pesqueiras. 
encontrar uma linha paralela e afastada 500,00 metros da Av. Alfredo Theodoro Born e da Estrada Costa do Retiro, seguindo, no sentido sudeste/noroeste, por esta linha até encontrar a BR-116. Ao oeste: inicia no encontro de uma linha afastada 500 metros a nordeste da Estrada Costa do Retiro com a BR-116, seguindo, no sentido sudoeste/nordeste, pela BR-116 até o encontrar o Arroio Corrientes.

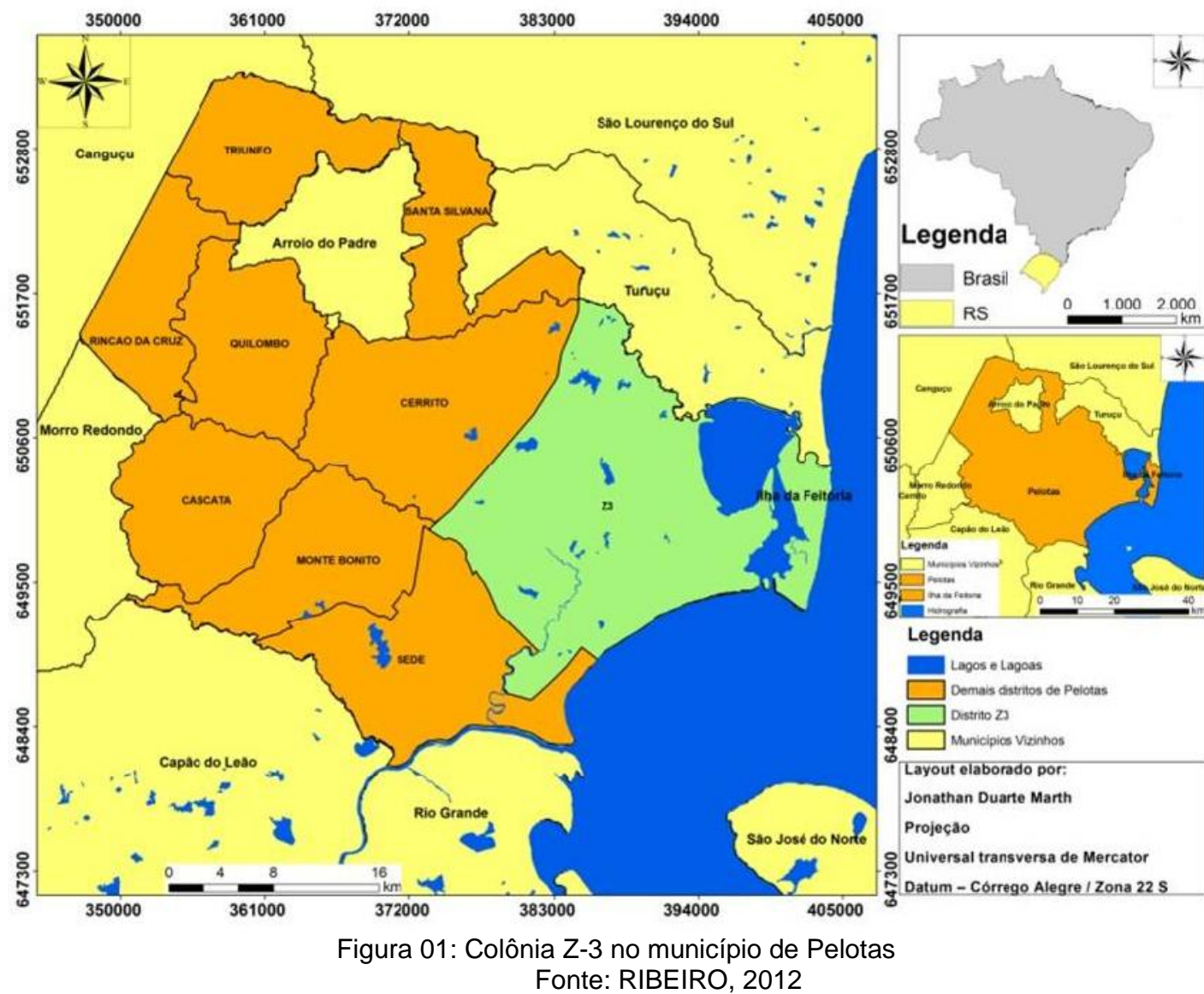

Esse território político-administrativo estabelecido em legislação municipal é também lugar de resiliência por parte da comunidade da Z-3 a contínuos ataques ao território da pesca artesanal por parte de políticas governamentais de regulação ambiental. É neste território também que sobrevivem identidades territoriais fundadas em processos de reterritorialização contra-hegemônicos que insistem em teimosia e procissão, fazendo dos ciclos naturais seus próprios ciclos, ouvindo anúncios de anjos e convivendo entre bruxas, lobisomens e assombrações (Ribeiro, 2012).

\subsection{A água como destino}




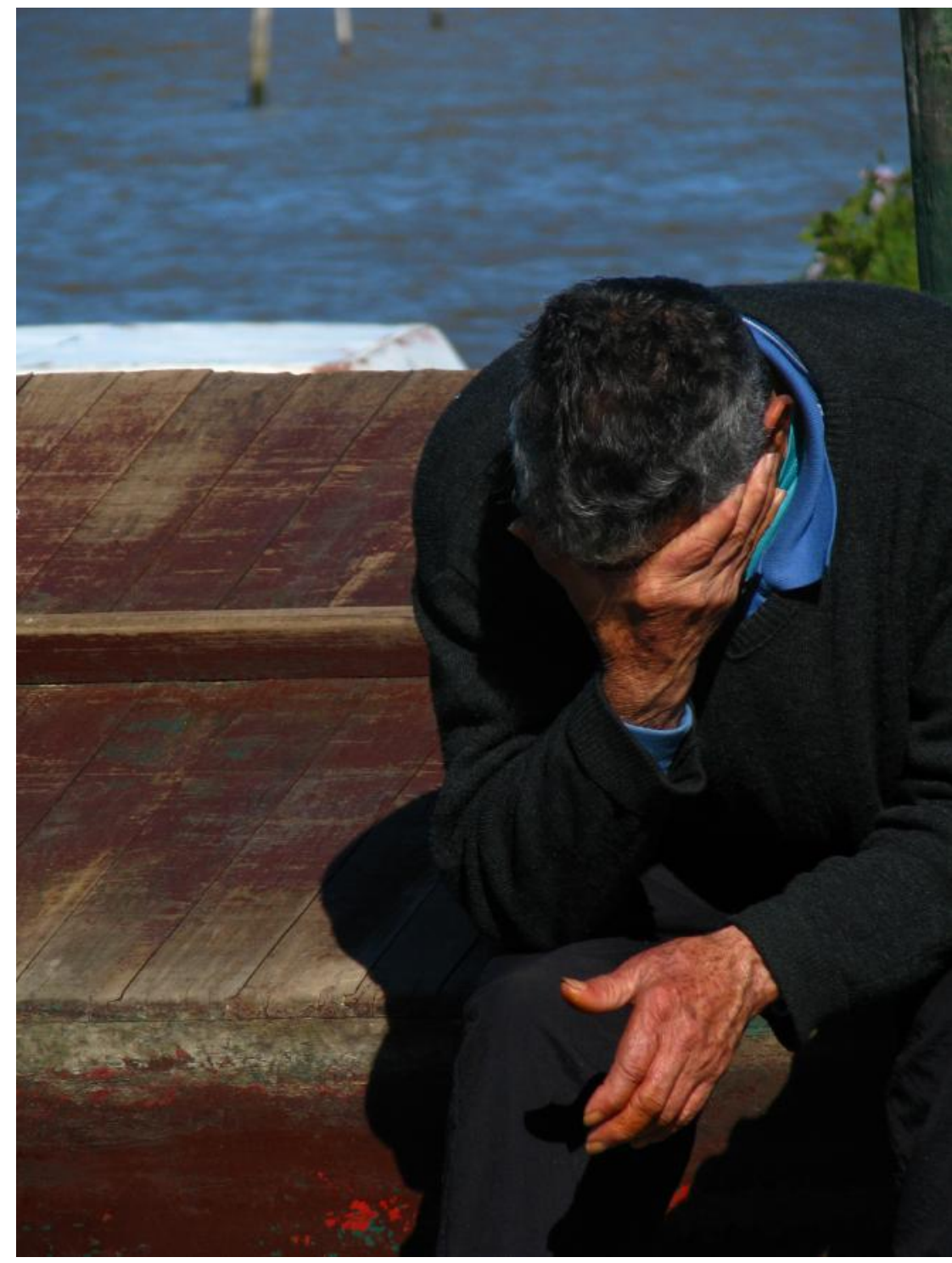

Figura 02: Colônia de Pescadores Z-3 em tempos de "defeso"

Foto de Roberta Cadaval

O coletivo pesqueiro que habita a Colônia Z-3 possui redes sociais baseadas em relações de parentesco e reciprocidade, sendo que essas pessoas praticam a pesca artesanal ${ }^{8}$ em botes na Lagoa dos Patos, por eles chamada de mar $^{9}$.

\footnotetext{
${ }^{8}$ Devido às atenuantes crises de escassez da pesca, principalmente no que refere à safra do camarão, alguns pescadores artesanais da Colônia Z-3 trabalham em algumas temporadas, como empregados de embarcações que pescam no oceano, principalmente no município de Rio Grande/RS/Brasil. Sobre isso ver o artigo "Territorialidade e conflito na pesca embarcada: um estudo de caso sobre os pescadores de São José do Norte-RS e suas analogias sobre animais marinhos", de Gianpaolo Adomilli, disponível em http://repositorio.furg.br/bitstream/handle/1/1269/Territorialidade\%20e\%20conflito\%20na\%20pesca\%20em barcada\%20um\%20estudo\%20de\%20caso\%20sobre\%20os\%20pescadores\%20de\%20S\%C3\%A30\%20 J
} 
Segundo o Censo Demográfico (2000) a população total é formada por 3.221 habitantes. Não há dados exatos da porcentagem desta população que pode ser classificada como pescadores artesanais. Levantamento do Sindicato dos Pescadores em conjunto com a Prefeitura Municipal de Pelotas e o Instituto Técnico de Pesquisa e Assessoria da Universidade Católica de Pelotas (ver ITEPA, 2002) indicaram a presença de 1.031 pescadores com carteira, contudo há motivos para supor que o número seja muito superior, visto que o levantamento não conseguiu abranger todos aqueles sem carteira (mulheres e jovens principalmente) ou que não possuem uma ligação direta com a captura, mas atuam nas demais atividades do Sistema Agroindustrial do Pescado (filetamento, salga, venda, etc.). Nossas estimativas permitem supor que praticamente todas as famílias estabelecem algum tipo de relação produtiva e reprodutiva com a atividade (NIERDELE; GRISA, 2006, p.04).

Em campo etnográfico, os pescadores e as pescadoras da Colônia Z-3 nos explicavam acerca dos ciclos de vida das espécies por eles capturadas. Diziam-nos que no verão com a diminuição do nível da água do mar (lagoa dos patos), a água do oceano salga a água doce. Junto com a água salgada do oceano entram os peixes de água salgada e os camarões, cuja captura deveria colocar-se como principal fonte de renda do pescador e da pescadora da Z-3. No entanto, se há excesso de chuvas na primavera a água não salga. Nesse contexto, de acordo com os pescadores e as pescadoras da Z-3, persiste um descompasso entre as variações nos calendários de salga do mar e as estanques e homogêneas legislações ambientais que ignoram os conhecimentos e calendários tradicionais da pesca artesanal ${ }^{10}$. Nas entrevistas realizadas na colônia, essa questão parece colocar-se como pano de fundo das constantes crises vivenciadas repetidamente nos últimos anos nessa comunidade.

Para Moura (2012), ainda que o território tradicional aquático e o calendário tradicional de pescadores artesanais venham sendo tomados de interesse na literatura científica e internacional, "[...] o volume de informações ainda está aquém da importância de ambos no reconhecimento dos direitos destas populações em viverem

os\%C3\%A9\%20do\%20Norte\%20e\%20suas\%20analogias\%20sobre\%20animais\%20marinhos.pdf?seque $\underline{\text { nce }=1}$, acesso em 12/09/2017.

${ }^{9} \mathrm{O}$ coletivo costeiro que habita a Colônia Z-3 referem-se a Lagoa dos Patos como mar. Por este motivo, adotamos tal categoria neste e outros textos de nossa autoria. Desta forma, salientamos que quando utilizarmos a palavra "mar" estaremos nos referindo à Lagoa dos Patos.

${ }^{10}$ Os livros "Águas da Coréia: Uma viagem ao centro do mundo em uma perspectiva etnooceanográfica" e "Guerra nos mares do sul: O papel da oceanografia na destruição de territórios tradicionais de pesca", de autoria de Gustavo Moura (2012; 2017), abordam com profundidade os ciclos de mudanças ecológicas percebidos pelos pescadores na construção e apropriação territorial do espaço da pesca. Tal discussão ira se colocar na ordem de uma "etnocronologia estuarina". 
e manejarem os recursos naturais de seus territórios tradicionais conforme as tradições" (MOURA, 2012, p. 17).

Nesse cenário, o seguro-defeso, legalmente estabelecido como uma renda destinada aos pescadores nos períodos de proibição da pesca por ocasião dos períodos reprodutivos das espécies, vem sendo concedido algumas vezes em períodos de crise da pesca. Tal concessão é esporadicamente alcançada como resposta às persistentes lutas da comunidade por acesso a subsídios de subsistência em tais períodos. Entretanto, a concessão do seguro pressupõe a proibição da pesca. Muitos dos pescadores e pescadoras, por estarem com algum problema de documentação ou por morosidades de ordem burocrática, não conseguem acessá-lo, mesmo assim, permanecem proibidos de pescar.

Em algumas ocasiões, como última estratégia de sobrevivência, acabam praticando o que os órgãos governamentais regulatórios definem como "pesca predatória"11, manifestação do processo de modernização da pesca, apoiada pelo Estado, que unifica os incentivos governamentais às empresas, sem regulação de sua atividade, jogando à margem da sociedade o pescador e a pescadora artesanal e suas desesperadas práticas de sobrevivência.

\begin{abstract}
Cena freqüente no estuário da Laguna dos Patos é a ocorrência da pesca de espécies que não chegaram ao tamanho ideal. Embora a opinião pública culpe os pescadores artesanais - únicos a serem fiscalizados praticando o ato, pois a fiscalização das empresas como já foi dito é ineficiente e/ou inexistente dependendo da região - a origem do problema está justamente nas embarcações industriais que se concentram próximas ao canal de entrada da água do mar na Lagoa, impedindo a passagem dos peixes para o estuário. A redução do estoque de peixes na Lagoa obriga os pescadores a capturar peixes menores para compensar as perdas e alcançar um nível mínimo de renda. (NIERDELE; GRISA, 2006, p.22)
\end{abstract}

Trata-se do que Bernardo Mançano Fernandes (2008) chama de políticas neoliberais de desenvolvimento territorial. Ou seja, territórios são subalternizados por ocasião de empreendimentos realizados entre Estado e capital. O capital assim mantém o controle do território por meio das tecnologias e do mercado, e o pescador artesanal sofre processos de desterritorialização, sendo muitas vezes criminalizado perante sua própria comunidade.

Nesse contexto de conflitividade e tentativas de sobrevivência entre mar e terra, o coletivo da Colônia Z-3 vai vivenciando contínuos processos de

\footnotetext{
${ }^{11}$ Qualquer pesca feita fora do período determinado pelo IBAMA ou que se utilize de redes ou técnicas não permitidas (FIGUEIRA, 2000).
} 
desterritorialização e reterritorialização. Nesse movimento podemos perceber temporalidades distintas e complementares se elaborando na Colônia Z-3 ao longo do ano.

O tempo das safras é uma época em que não se percebe muitos homens ${ }^{12}$ nas ruas da colônia. Nas reuniões dos sindicatos e outras associações, as mulheres são maioria, bem como nas reuniões da escola. A "Divinéia", cais onde os botes ficam atracados, fica em quase abandono, assim como os galpões de reforma de barcos não permanecem tão povoados como na época em que os pescadores estão em terra.

Já em épocas de proibição da pesca, "época do defeso", os homens se fazem mais presentes. Entretanto, eles ainda permanecem minoria em espaços públicos como a escola e a Unidade Básica de Saúde. Em terra habitam as frentes das casas, os galpões, onde remendam redes, e os espaços em torno dos barcos atracados, realizando alguns reparos, esperando no ritmo das temporalidades governamentais que os separam do mar.

Nesse período, a Divinéia povoa-se de botes e da ansiedade dos homens que parecem sentirem-se constrangidos em terra. Enquanto o "ethos pescador" parece estar intimamente ligado ao território aquático, por sua vez, o "ethos pescadora" engloba o espaço da terra e do mar. Nesse cenário, os filhos parecem não se adaptar a presença constante do pai em casa, e as mulheres seguem tomando a maior parte das decisões familiares, mesmo com a presença do companheiro em casa.

A relação dos habitantes da Colônia de Pescadores Z-3 com a pesca extravasa o vinculo econômico de trabalho, suas vidas pulsam na rítmica dos ciclos de vida e morte do mar. A água para essas famílias é um destino, um devir, e, assim como na poética de Bachelard (1997), é elemento transitório, metamorfose ontológica essencial entre fogo e terra, sendo o ser votado à água, um ser em vertigem. Á água, por seu poder de refletir, é para o autor, um céu invertido. Com seus reflexos a água duplica o mundo, duplica as coisas, duplica a imaginação do sonhador navegante envolvendo-o numa intensa experiência onírica.

\footnotetext{
${ }^{12}$ É importante deixar claro que apesar de grande parte da comunidade que sai ao mar para a captura dos peixes se configurar em um grupo masculino, há uma constante presença da mulher nas atividades pesqueiras, tanto na captura direta do pescado, quanto no trabalho de processamento feito em terra. São as mulheres também que cuidam do cotidiano da Colônia Z-3, fazendo a gerência dos ciclos familiares e comunitários em consonância com os ritmos de captura dos peixes. Desta forma, entendemos que as mulheres em ações diretas ou indiretas estão profundamente inseridas nas atividades pesqueiras da Colônia Z-3, sendo por nós compreendidas enquanto pescadoras.
} 
Antonio Carlos Diegues (1996) explica que são muitas as análises sobre a relação entre o homem, os mares e as ilhas em seus aspectos simbólicos, míticos e imaginários, o que exige certo pluralismo metodológico para uma mínima compreensão. Nesta perspectiva, o psicólogo Jacques Laberge (2000), no texto "As naturezas do pescador", fala sobre a autoimagem do pescador.

\begin{abstract}
Corajoso como herói de guerra, mais livre que o operário, a polícia, o cozinheiro, o cobrador de ônibus, o garçom de restaurante, mais sabido e artista que o agricultor, o pescador é o melhor. Isto é, toda a apresentação do mar, das águas, do peixe como ameaça e perigo, como mistério a perscrutar, como arte à disposição do artista tem um objetivo: mostrar quão valoroso é o pescador, quão interessante é o seu trabalho. Tanto mais perigoso, quanto mais interessante. A aproximação do perigo, perigo da morte afinal, é algo que o pescador costuma associar à sua profissão (LABERGE, 2000, p. 43).
\end{abstract}

Lucas $^{13}$, um dos pescadores que conhecemos em nossas etnografias, fala sobre a profissão do pescador afirmando ser este um "bom trabalho", pois, em suas palavras, "tu não tens patrão, tu escolhe o teu tempo de trabalho, tu escolhe tudo". Ao mesmo tempo, o narrador fala sobre o perigo que o pescador enfrenta cada vez que entra no mar. Lucas demonstra esse perigo quando conta sobre diversos acidentes e mortes ocorridos na Lagoa dos Patos com amigos e conhecidos seus. Ser pescador é ser forte e heróico o bastante para enfrentar esses perigos no cotidiano do trabalho.

Mais do que enfrentar os perigos do mar, Lucas demonstra em sua fala que o que torna o pescador um herói é persistir nesta atividade para além dos sérios conflitos com os órgãos governamentais regulatórios da pesca enfrentados por esses trabalhadores nos dias de hoje. Lucas, assim como os outros pescadores que conhecemos na Z-3, mostra-se muitas vezes "desencantado" com as crises da pesca e os riscos que eles enfrentam. Perigo em morrer em um acidente no mar, perigo na não garantia da subsistência da família, risco iminente em ver sua profissão extinta. Ao mesmo tempo, apesar dos riscos diários, eles não desistem efetivamente da atividade pesqueira. Lamentam a vida difícil no mar, mas em terra, aguardam ansiosamente pelo início de uma nova safra.

Laberge (2000) diz que por ter o pescador uma identificação com o silêncio das águas, acaba tendo dificuldade de se familiarizar com a vida mais agitada da terra. Nesse sentido, Câmara Cascudo (1954), no livro "Jangada: uma pesquisa etnográfica", se refere ao pescador como um "profissional do silêncio".

\footnotetext{
${ }^{13}$ Todos os nomes utilizados são fictícios.
} 
Cascudo diz que "o jangadeiro deve ser silencioso no meio da musicalidade selvagem do mar. É o único trabalhador que não pode conversar, nem cantar enquanto leva sua tarefa. [...] O ressoar da voz humana afugenta o peixe." (p.18 e 19). Uma cumplicidade silenciosa liga o pescador ao mar.

Durante as etnografias na Z-3 tivemos essa mesma impressão, ou seja, a existência e a perpetuação de um silêncio sob o universo masculino. Ao mesmo tempo em que nas rodas de chimarrão das mulheres, havia uma mistura de murmurinho e algazarra constante, onde as vozes de todas se embaralhavam falando sobre a vida na colônia, nos grupos de homens podiam ser escutadas poucas vozes, sempre em tom baixo. Sobre as simbologias que caracterizam as naturezas do pescador, Laberge (2000, p. 45) diz o seguinte:

Chuva e água, sol e água, noite e água. Pode faltar o peixe, pode romper a rede, mas nunca este contato direto com a natureza: sol-chuva-noite-água. A água, sempre a água. Que influência tem sobre uma pessoa dez, vinte, trinta, quarenta anos de sol causticante, implacável, de silêncio da noite, de contato constante com esta água misteriosa, detentora de sua sobrevivência?

Para esse autor, este "afastamento" do pescador em relação ao mundo da terra, ultrapassa a compreensão do comportamento. Com efeito, as águas não são simplesmente as águas, tanto elas quanto seus habitantes são perpassados por constantes e complexos simbolismos e personificações que influenciarão diretamente a forma como os coletivos costeiros vinculam-se aos seus territórios.

\subsection{Do universo do rito e do mito na formulação de uma territorialidade resiliente ${ }^{1415}$}

\footnotetext{
${ }^{14}$ Este capítulo traz algumas das questões abordadas na dissertação de mestrado intitulada "Bruxas, Lobisomens, Anjos e Assombrações na Costa Sul da Lagoa dos Patos - Colônia Z3, Pelotas: Etnografia, mitologia, gênero e políticas públicas", de autoria de Angelita Soares Ribeiro, sob a orientação do Profo Dr. Rogério Reus Gonçalves da Rosa. (Dissertação- Programa de Pós-Graduação em Ciências Sociais da Universidade Federal de Pelotas. Pelotas, 2012).

15 A dissertação intitulada "Pessoas, Sereias e Divindades: Um estudo etnológico, mitológico e etnooceanográfico em uma colônia de pescadores no sul do Rio Grande do Sul", de autoria de Carolina Amorim, sob a orientação do Profo ${ }^{\circ}$ Dr. Rogério Reus Gonçalves da Rosa e Co-Orientação do Profo Dr. Gustavo Moura, defendida em agosto de 2017 junto ao Programa de Pós-Graduação em Antropologia (PPGAnt), da UFPel, dialoga diretamente com as questões abordadas nesse texto.
} 


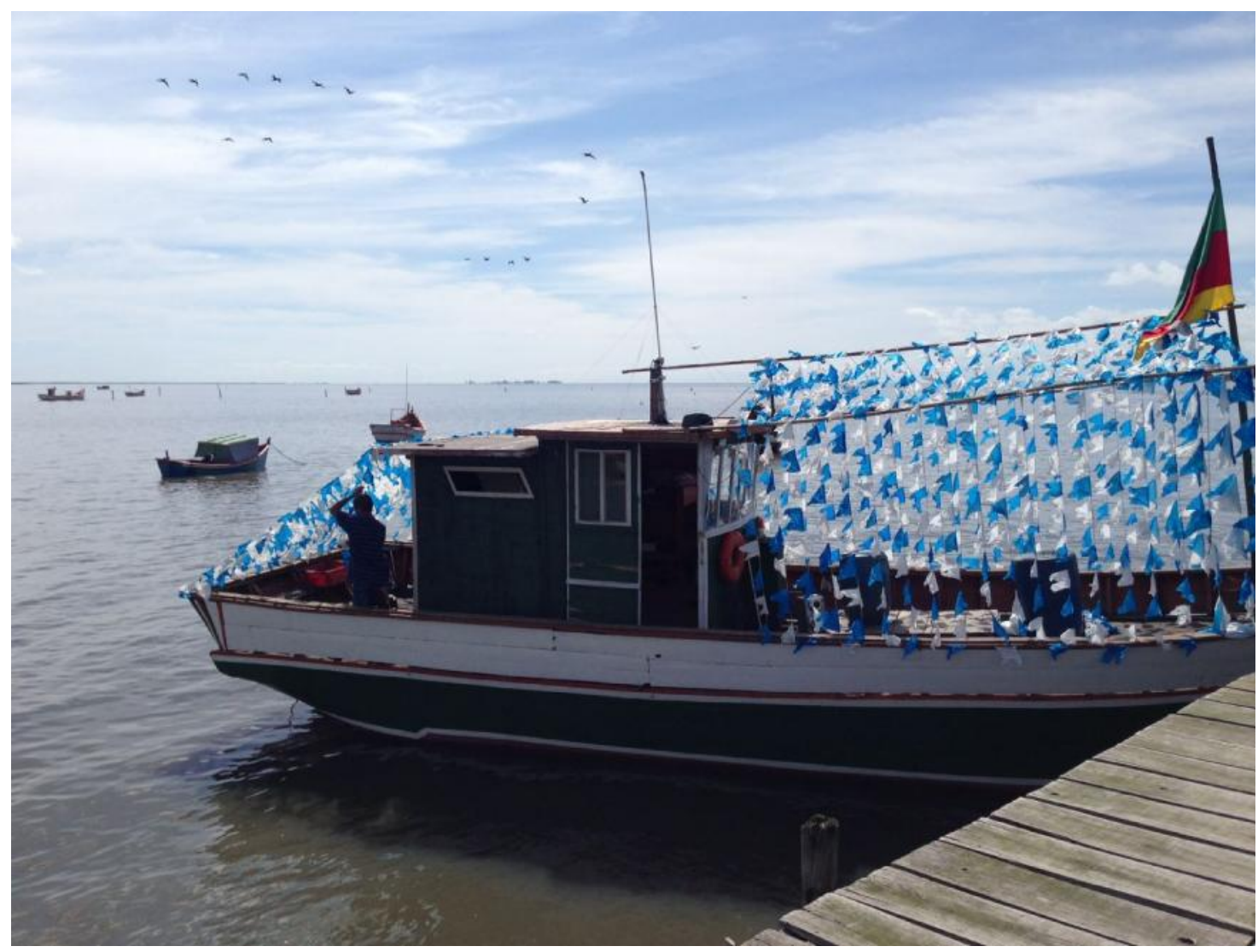

Figura 03: Bote enfeitado para a Procissão de Nossa Senhora dos Navegantes na Colônia de Pescadores Z-3.

Foto: Carolina Amorim da Silva Bittencourt

Em cada caso concreto, ao se examinarem os fatores por trás de processos de territorialização, descobriremos, recuando no tempo e escavando o suficiente, um emaranhado de razões e motivações. A defesa de uma identidade pode estar associada a uma disputa por recursos e riquezas, no presente e no passado; a cobiça material não é, de sua parte, descolável do simbolismo, da cultura. (SOUZA, 2009, p. 60).

No subtópico anterior procuramos demonstrar os modos como a vida num território limiar entre terra e mar vinculam os pescadores e pescadoras da Colônia Z-3 ao destino das águas. Do silêncio dos homens ao burburinho da gestão da vida da colônia realizado pelas mulheres, as idas e vindas do mar vão formulando e fortalecendo vínculos com o território que extravasam os limites de acesso político e econômico ao território da pesca. O coletivo costeiro que habita a Colônia de Pescadores Z-3 vai se apropriando desse território através de territorialidades que em resiliência permanecem, produzindo sentidos outros- tão necessários- à sobrevivência nesse lugar. Ou seja, ainda que soterrado por territorialidades baseadas em um 
Estado-Nação, permanece vivo aqui um ethos costeiro formulado em modos de vida que, em dádiva com os ciclos do mar, reafirma uma ideologia territorial que persiste frente a um frágil poder de acesso político e econômico ao território da pesca.

Compreendemos que tal identidade territorial formula-se a partir do vínculo ecológico da comunidade com o ecossistema que a circunda, como também, a partir de uma forte cosmologia costeira que irá se formular do simbólico/mítico a todas as esferas do viver, saber e fazer desses pescadores e dessas pescadoras.

É o que ocorre no dia dois de fevereiro de todo ano, dia em que se comemora nesse território a Festa de Nossa Senhora dos Navegantes, atribui-se um sentido sagrado para o mar. Nesse dia, em reciprocidade com Nossa Senhora, os moradores da Z-3 oferecem procissões e festejos à santa, esperando em troca abundância do pescado e melhorias nas condições de vida dos pescadores.

Nos dias anteriores a festa pode-se perceber uma movimentação em torno dos preparativos. Os botes passam por uma nova pintura e são enfeitados com bandeiras azuis e brancas. As casas também são decoradas e o festeiro do ano ${ }^{16}$ se ocupa com a compra das tainhas a serem assadas e com a estrutura que é montada em torno da Igreja Católica João Paulo II. Isso acontece para que no dia seguinte tudo esteja pronto para fazer parte do ritual da procissão de Nossa Senhora dos Navegantes pelo mar doce.

Nos anos de 2010, 2011 e 2012, participamos da procissão no bote do Lucas, pescador já apresentado nos subtópico anterior. O embarque no bote sempre se fez enquanto um cômico evento de dificuldade para nosso grupo desacostumado com a rítmica das ondas. Assim que todos se colocavam a bordo, Lucas andava um pouco mais para o meio do mar, soltava a âncora e esperávamos os barcos saírem da Divinéia com a Santa. Com o motor desligado o bote balançava bastante, alguns de nós se acostumavam com o balanço, outros permaneciam agarrados à borda do bote ou ao banco. Nesses instantes de espera e silêncio, olhávamos para a Colônia Z-3 "da água para a terra", diferente de todos os outros dias que estivemos ali. Aos poucos o silêncio era rompido pelo som dos motores dos outros barcos que se aproximavam, e, toda nossa ansiedade ia dando lugar a um certo fascínio pela cinematográfica paisagem que ia se revelando. Foguetes se faziam ouvir, Nossa Senhora dos

\footnotetext{
${ }^{16} \mathrm{O}$ festeiro do ano é aquele morador que se encarrega de organizar a festa em torno da igreja e da procissão da Santa pela Lagoa dos Patos.
} 
Navegantes havia saído do cais. Hora de puxar a âncora e ligar os motores para, em crença e reza, acompanhar a Santa até seu encontro com lemanjá.

O encontro entre a santa católica Nossa Senhora dos Navegantes e a orixá, lemanjá ocorre no balneário dos Prazeres, mais conhecido como Praia do Barro Duro. Quando se chega de bote a este balneário pode-se perceber um mar de gente misturando-se ao mar das águas da lagoa. Os fiéis no Barro Duro não estão em botes como os pescadores e pescadoras da Z-3, sendo que seus corpos emergem nas águas, o território de lemanjá. Nos três anos em que acompanhamos a procissão, podemos testemunhar somente uma ocasião em que lemanjá foi levada ao encontro de Nossa Senhora dos Navegantes em uma pequena embarcação sem motor, carregada nos ombros por seus fiéis e, em nas outras duas ocasiões em um bote, tal qual a santa católica. Entretanto, mesmo com lemanjá "embarcada", os fiéis permaneciam imersos na água e não em botes como fazem os pescadores e pescadoras da Colônia Z-3.

O encontro entre as duas entidades é motivo de grande emoção por parte das pessoas, e todas permanecem em silêncio e devoção enquanto as duas rainhas giram uma em torno da outra. Ainda que na ordem dos ritos terrestres, as duas sejam cultuadas em territórios distintos, no território aquático, as duas parecem renovar o pacto anual de proteção de seu povo ${ }^{17}$.

\subsection{Do rito de Nossa Senhora dos Navegantes a certas narrativas mitológicas na}

\section{Colônia Z-3}

Consoante com essa dimensão ritualística que se percebe durante o dia dois de fevereiro em homenagem a Nossa Senhora dos Navegantes, estão os mitos narrados neste território, apontando relações de alteridade entre humanos e nãohumanos na Colônia Z-3. Nas palavras de Rosa:

Os mitos são narrativas que apontam à origem, o destino, à eternidade, às trocas simétricas e assimétricas, ao processo de comunicação de humanos e não-humanos em um dado território. Já a cosmologia, refere-se a teorias acerca do mundo, em especial, sobre a forma, o conteúdo e o ritmo do universo (2011, p.101).

\footnotetext{
${ }^{17}$ Acerca do encontro entre Nossa Senhora dos Navegantes e lemanjá, ver o artigo "Cruzamentos, territórios e patrimônio religioso: sobre a doçura como referência cultural nas comemorações de lemanjá e Nossa Senhora dos Navegantes nas praias do Laranjal, Pelotas/RS, em 2007", de MARíLIA FLOÔR KOSBY. Disponível em https://www.revistas.usp.br/cadernosdecampo/article/download/47042/50765, acesso em 19/09/2017.
} 
Nesse território da Colônia Z-3, a bruxa é personagem central nas narrativas que ouvimos entre as pessoas. A mãe de Lucas, pescador citado no subtópico anterior, nos contou acerca de um caso de embruxamento de um de seus netos.

\begin{abstract}
Eles moravam aqui nos fundos. Que o Chiquinho era pequeno... Todos os dias tiravam o Chiquinho da cama e botavam ele embaixo da cama. E o guri aparecia todo roxo no outro dia. E elas diziam que eram as bruxas que chupavam ele. Aí ensinaram nós a botar milho, me parece ou arroz na porta da casa. Alpiste. Eu sei que até bacia com água nós botava. Pra espantar elas. Sim, alpiste, assim, na porta, pra elas não entrar. Que aí diz que elas ficavam comendo ali e não entravam. Acho que elas comem... Não sei. Por isso que elas podem ser alguma ave que come alpiste. Como é que gente vai comer alpiste? Isso aí, eu não sei direito o que é. Eu sei que ele aparecia seguido... Ela botava ele na caminha e ele chorava, chorava... Ela ia procurar ele e estava embaixo da cama... Pequenininho, recém nascido. Como é que ele ia sair da cama? E ele era bem clarinho e aparecia todo roxo. Meu neto. Filho do me guri que mora no Areal.
\end{abstract}

O lobisomem também aparece como central nas narrativas, eliminando o tom grave presente nas histórias sobre bruxas, e, evocando jocosidade entre os narradores. Nas palavras de Lucas:

\begin{abstract}
Se aqui tem lobisomem, ele é pescador, né? Eu acho que eu não sou. Não sei, né?(risos). O que tinha aqui que diziam que era lobisomem já morreu. Dizem que tem, eu nunca ví. Mas se tem eu não quero ver também, né? Esse mesmo, o meu cunhado, diz que viu um barulho na frente da casa. A minha irmã mora nessa rua do meio aqui... Diz ele que escutou um barulho e que tinha um baita dum bicho assim, e que era um lobisomem. Aí nós ficamos mexendo com ele: 'Quê, viesse pra cá uns pouco dias e já tá vendo lobisomem?' (Risos). Ele disse que já viu duas ou três vezes.
\end{abstract}

Para Suzana Araújo, as narrativas sobre as bruxas e os lobisomens estão inseridas no mesmo complexo de significações. Ou seja, tais narrativas irão se colocar no jogo de construção das identidades masculina e feminina dos moradores da llha da Pintada, em Porto Alegre, Rio Grande do Sul. Assim como na Colônia Z-3, na Ilha da Pintada histórias de lobisomens ocorrem paralelas às histórias de bruxaria e um assunto sempre implica o outro. Araújo evidencia nas narrativas de seus interlocutores vários "pares de oposição entre os dois personagens, ou seja, princípios de classificação que organizam as práticas e as crenças dos moradores: (bruxa $x$ lobisomem); (casa $x$ rua); (feminino $x$ masculino); (dia $x$ noite); (imanência $x$ transcendência)." (ARAÚJO, 2007, p 59).

$\mathrm{Na}$ Colônia Z-3, as bruxas se apresentam de maneira mais visível nas narrativas e nos eventos vivenciados pelos moradores do que o lobisomem. A bruxa é uma figura de mais poder e perigo, já que pode adentrar o espaço doméstico. A bruxa mata, o lobisomem assusta. Assim, podemos dizer que apesar de, na perspectiva 
sociológica, o ritmo da gestão feminina da vida na colônia ser englobado pela rítmica do território masculino marcado pelas idas e vindas do mar (território predominantemente masculino), na ordem mitológica essa relação se inverte de modo que a bruxa (feminino) passa a englobar seu contrário, o lobisomem (masculino).

Os espíritos de crianças também habitam a Colônia Z-3, e com recorrência ganham vida nas histórias que ouvimos.

\begin{abstract}
Na minha rua tem um gurizinho que corre de um lado para o outro só de calçãozinho. Ele tem os cabelos bem loirinhos e cacheado. Um dia ví ele passar e fiquei esperando pra ver de onde ele ia sair... Mas daqui a pouco ele já passou correndo para o outro lado. Na minha rua todo mundo vê ele. Eu acho que ele é um anjo...
\end{abstract}

Na figueira tem uma guriazinha que fica se balançando num galho.

E tem aquelas crianças que caminham de mãos dadas no Totó. Tem também uma guriazinha que chora toda vez que alguma coisa ruim vai acontecer. Me arrepio toda só de falar.

Sempre à noite, esses anjos adentram os pátios, cruzam os caminhos de pescadores e pescadoras, choram para anunciar a morte e assim torná-la menos dolorida nessa comunidade. A partir das falas dos narradores podemos pensar esse ente mítico como o conjunto de espíritos de crianças mortas que se relacionam com os humanos para lhes causar o bem, já que ao chorar antes de uma morte ele prepara e acolhe com zelo a família que vai perder um ente querido.

A relação do coletivo habitante da Z-3 com a Ilha da Feitoria também aproxima o campo das (des/re)territorializações materiais ao campo do mítico. Tal ilha está localizada à uma hora de barco da Colônia Z-3 e possuía até o início da década de setenta, atividades de comércio e organização social muito forte. Para Moura, Bairros e Sperling (2007), diante das dificuldades de deslocamento à zona urbana, entre outros recursos, os moradores a abandonaram, migrando para a Colônia Z-3 e para outras comunidades pesqueiras localizadas em cidades como São Lourenço do Sul. Entretanto, questões de ordem mitológica também podem estar associadas ao abandono da ilha. Lucas também nos narra sobre a Feitoria:

Contam que aparece... Que aparece assombração... Na igreja lá... Os cara dormiam na igreja e dizem que escutam direitinho caminhando dentro da igreja. Esses que moram aqui do lado eram de lá. Tu escuta assim e não vê nada assim... E os cara dizem que fazem barraca lá em terra e que jogam 
areia em cima da barraca. Porque naquela ilha aconteceu um monte de coisa lá, né? Aconteceu um incêndio e morreu duas ou três mulheres. Morreu a mãe, a filha e a sobrinha, parece que foi. Incendiou. Essas geladeiras que eram com gás, né? Pegou fogo no bujão. Não, o do bujão é o do guri que mora com o Laércio... Pegou fogo na geladeira, explodiu e pegou no pai e no filho... Eles são todo queimado, eles moram aqui. É o Laércio e o Irací, eles ficaram todo queimado. Isso aí tu pergunta pra outros que eles vão te contar, até melhor que eu. Faz anos isso. E essa outra família pegou fogo. Não sei se foi uma vela que pegou fogo ou um desses bujãozinho, liquinho. Aí morreram, essas morreram. Esses outros não, porque se jogaram na água. lam assim, pegando fogo, e se jogaram na água. O Laércio esse, tem um lado todo enrrugado, todo queimado assim. Teve dois incêndios. Que eu me lembro foi dois. E lá morava muita gente, né? Aí pegou a acontecer coisa lá e as pessoas passaram a se mudar. Veio um pouco pra cá, um pouco foi pra São Lourenço.

Seu Adão, que morou na ilha até seus vinte e oito anos, também nos conta sobre aquele assombrado território.

\begin{abstract}
Morreu muita gente lá! Então hoje é difícil sair uma pessoa daqui e ir lá e dizer que não viu alguma coisa lá! [...] É! Apavorou um pouco o pessoal, incendiou as casa e outras coisas mais lá também que aconteceram, muitas pessoas adoeceram! Lá mesmo, lá foi... Esse sobrado eu queria que vocês vissem... Aquilo foi feito em época de escravo, foi construído por escravo! A senzala mesmo que tinha lá, que tinha uma senzala lá, eu cansei de vê, inclusive depois que abandonaram, disseram que tinha lá dinheiro, que tinha muito dinheiro lá em baixo!
\end{abstract}

Ainda que a presença açoriana demarque visiveis traços nas manifestações culturais da Colônia Z-3, manifesta em muitos dos costumes e nas repetidas histórias de bruxas e lobisomens, a presença afroameríndia também se coloca dos vestígios materiais $^{18}$ às narrativas mitológicas. Nesse cenário surgem narrativas sobre bandos de índios que passam cavalgando e gritando em correria, e escravos que caminham arrastando correntes, guardando tesouros. Compreendemos assim que estas narrativas que surgem, não configurando elementos repetidos nos mitos de matriz européia, denotam a elaboração de um conjunto de mitos que surgem da congruência dos diversos povos étnico-raciais que habitam/habitaram a costa da Lagoa dos Patos $^{19}$.

Em contato com a comunidade, percebemos que a identidade territorial deste coletivo costeiro também se configura a partir desse conjunto de narrativas míticas.

\footnotetext{
${ }^{18}$ Para Rafael Milheira (2011), pode-se afirmar a presença no entorno da Laguna dos Patos de indígenas do grupo de construtores de Cerritos e também de Arachanes, Tapes e Patos- que originaram o que hoje chamamos de povo Guarani. Sítios arqueológicos foram localizados na llha da Feitoria e na Praia do Totó (praia localizada entre o bairro Barro Duro e a Colônia Z3). A forte presença de água na região pode ter sido um dos elementos que fez as comunidades se fixarem por aqui. (MILHEIRA, Rafael. MARINHO, J. R. Amaria. Diário Popular, Pelotas, 27 de agosto de 2011. Diário Popular 121 anos, p 03. A pré-cidade: A Pelotas antes de Pelotas).

${ }^{19}$ Para saber mais sobre os grupos étnicos que já habitaram a costa da Lagoa Patos, ver ADOMILLI (2002) e MOURA (2012).
} 
Assim sendo, insistimos, a relação que os habitantes da Colônia de Pescadores Z-3 estabelecem com seus seres e lugares mágicos, atravessa a elaboração de suas territorialidades, interferindo em seus modos de vida e práticas de trabalho. Percebese isso em narrativas sobre famílias que deixaram de morar ou trabalhar na Ilha da Feitoria por ser esse um território assombrado. Ou então quando a morte neste território é anunciada por personagens anjos que correm pela colônia "quando algo ruim vai acontecer". As narrativas míticas ou lendárias reafirmam também um poder feminino presente na colônia, onde o lobisomem pode ser identificado através de conhecidos ritos de descobrimento, enquanto as bruxas só podem ser nomeadas e "vencidas" pelas mulheres benzedeiras.

É neste território onde a pesca artesanal luta por persistir frente às políticas neoliberais excludentes, onde barcos saem em procissão em busca de uma safra abençoada por Nossa Senhora dos Navegantes e por lemanjá, onde bruxas e lobisomens dividem espaço com humanos, onde crianças invisíveis balançam-se em árvores e correm pelas ruas, que territorialidades se configuram na Colônia de Pescadores Z-3. Territorialidades elaboradas entre o mar e a terra, entre o sagrado e o trabalho, entre o moderno e o tradicional, entre o humano e o não-humano.

\section{Considerações finais}

Esse texto procurou percorrer um determinado campo teórico de formulação dos conceitos de território e territorialidade. Para isso, nos aproximamos do campo da geografia, em possibilidade de diálogo com a antropologia, pensamos a dimensão do poder em enfoque por vários do autores, transitamos entre abordagens que ora privilegiam uma dimensão do território, ora outra, e nos vinculamos à abordagem de território de Haesbaert (2004) que congrega as dimensões econômica, política e cultural.

Nesse sentido, auxiliados pelo autor, demos ênfase à importância da dimensão cultural- que muitas vezes é relegada a uma menor importância que a dimensão econômica e a dimensão política- abordando o território como valor que denota uma territorialidade que, estabelecendo uma relação espiritual com os espaços de vida, torna-se relisiente ainda em contínuos processos de des/re/territorialização promovidos por um Estado moderno excludente e criminalizante das comunidades tradicionais e grupos populares. 
Diante a tal cenário, apresentamos o território da Colônia de Pescadores Z-3 a partir dos dados de etnografias realizadas entre os anos de 2010, 2011, 2012 e 2017. Partimos de dados sociodemográficos procurando apresentar a colônia em seu território político-administrativo, para, logo em seguida, apresentar os modos como prevalece na Z-3 uma ideologia territorial (HAESBAERT, 2004) formulada num território limiar entre mar e terra, captura dos peixes e gestão da colônia, masculino e feminino. Tais territórios não são analisados aqui como hierárquicos, antes complementares naquilo que entendemos como a totalidade da atividade pesqueira artesanal.

Ainda que pesem todas as dificuldades de sobrevivência diante ao processo de aniquilação dos territórios e conhecimentos tradicionais desse coletivo por ordem de um Estado que, como já enfatizamos, simultaneamente regula a pesca artesanal com o "punho forte" das legislações ambientais, e não coloca nenhum limite de acesso ao território da pesca para as empresas de pesca industrial, os pescadores e pescadoras resistem em seus vínculos territoriais. São heróis e vítimas do destino das águas.

Ainda que, com base em Moura (2017), os processos de territorialização estratégica do Estado Moderno prevaleçam em extermínio e barbárie sempre renovados, insistimos com o autor que resistem no mesmo cenário processos de territorialização tática, que emergem como reapropriação do espaço pelas populações tradicionais. São "[...] formas sub-reptícias (táticas) que atuam no campo paradoxal entre o visível, quando a resistência é aberta, e o quase invisível, quando a resistência é silenciosa" (2017, p.49).

Lembramos assim do silêncio dos homens da Z-3, que, complementado pelo burburinho feminino, nos ensina como ainda muito pouco sabemos das cosmologias e territorialidades que fazem com que se permaneça em uma vida em constante ameaça de sobrevivência. Em procissão por terra e mar, em fuga do lobisomem, sobrevivendo à bruxa, em rememoração do extermínio de ancestrais que retornam ainda acorrentados, mas, acalentados por anjos, esse coletivo permanece na costa desse mar ora doce, ora salgado. Suas cosmologias colocam-se como escudos silenciosos em um campo minado pelas (i)racionalidades do Estado Moderno e pelas epistemologias (pós)coloniais que o sustentam.

\section{Referências Bibliográficas}


ADOMILLI, Gianpaolo Knoller. Trabalho, Meio Ambiente e Conflito: um estudo antropológico sobre a construção da identidade social dos pescadores do Parque Nacional da Lagoa do Peixe - RS. Dissertação de Mestrado. PPGASUFRGS, Porto Alegre, 2002.

ARAÚJO, Susana de Azevedo. Paradoxos da modernidade: A crença em bruxas e bruxarias em Porto Alegre. Tese de Doutorado. PPGAS-UFRGS, Porto Alegre, 2007.

BACHELARD, Gaston. A Água e os Sonhos. Ensaio sobre a imaginação da matéria. São Paulo: Martins Fontes, 1997.

CASCUDO, Luis Câmara. Jangada: uma pesquisa etnográfica. Rio de Janeiro: Ministério da Educação e Cultura, 1954.

DIEGUES, Antônio Carlos S. O Mito da Natureza Intocada. São Paulo: Ucitec, 1996.

DIEGUES, Antonio Carlos. A imagem das Águas. São Paulo: USP, 2000.

FERNANDES, Bernardo Mançano. Entrando nos territórios do território. In: PAULINO, E. T.; FABRINI, J. E. (Orgs.). Campesinato e Territórios em Disputa. São Paulo: Expressão Popular/UNESP. 2008.

FIGUEIRA, L. D. Pesca Predatória: a Gênese Social de um Problema Legítimo. 2000. Monografia (Instituto de Sociologia e Política), UFPEL: Pelotas.

GALLOIS, Dominique. Mairi Revisitada. A reintegração da Fortaleza de Macapá na tradição oral dos Waiãpi. São Paulo: Núcleo de História e Indigenismo da Universidade de São Paulo: 1994.

HAESBAERT, Rogério. O Mito da Desterritorialização. Bertrand Brasil, 2004.

HAESBAERT, Rogério; LIMONAD, Ester. O Território em tempos de globalização. ETC... Espaço, tempo e crítica, n. 2, v. 1, p. 39-52, ago. 2007.

HAESBAERT, Rogério. Território e Multiterritorialidade: Um debate. GEOgraphia -

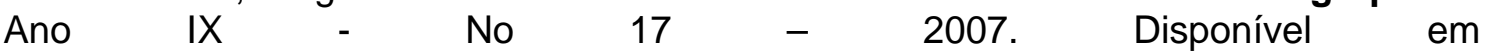
http://www.geographia.uff.br/index.php/geographia/article/viewFile/213/205, acesso em 11/09/2017.

LABERGE, Jacques. As naturezas do pescador. In: DIEGUES, Antonio Carlos. (org.). A imagem das Águas. São Paulo: USP, 2000.

MOURA, Gustavo G. M.. Águas da Coréia. Uma Viagem ao centro do mundo em uma perspectiva etnooceanográfica. Recife: Nupeea, 2012.

MOURA, Gustavo G. M.. Guerra nos mares do sul. O papel da oceanografia na destruição de territórios tradicionais de pesca. São Paulo: Annablume, 2017.

MOURA, Amanda; BAIRROS, Jacqueline Valle; SPERLING, Urania Pereira. Estudo sobre viabilide turística na llha da Feitoria a partir de entrevistas realizadas com ex- 
moradores, Pelotas / RS. In: Anais do XVI CONGRESSO DE INICIAÇÃO CIENTÍFICA, 2007, Pelotas.

NIEDERLE, Paulo André; GRISA, Catia. Transformações sócio-produtivas na pesca artesanal do estuário da lagoa dos patos, RS. Rev. eletrônica Mestr. Educ. Ambient. ISSN 1517-1256, v.16, janeiro junho de 2006.

RAFFESTIN, Claude. Por uma Geografia do Poder. São Paulo: Ática, 1993.

RATZEL, Friedrich. Geografia do Homem (Antropoeografia). In: MORAES, Antonio Carlos. Ratzel. São Paulo: Ática, 1990. P. 32-107.

RIBEIRO, Veridiana Soares. Reforma agrária e reorganização territorial: Um estudo de caso no assentamento 24 de novembro - Capão do Leão - RS. 2009. 85 f. Monografia (Instituto de Ciências Humanas- Licenciatura em Geografia) UFPel, Pelotas.

RIBEIRO, Angelita Soares Ribeiro. Bruxas, Lobisomens, Anjos e Assombrações na Costa Sul da Lagoa dos Patos - Colônia Z3, Pelotas: Etnografia, mitologia, gênero e políticas públicas. 2012. 121 f. Dissertação (Programa de Pós-graduação em Ciências Sociais-Mestrado) UFPel, Pelotas.

ROSA, Rogério Reus Gonçalves da. Mitologia e Xamanismo nas relações sociais dos Inuit e dos kaingang. Espaço Ameríndio, Porto Alegre, v. 5, n. 3, p. 98-122, jul./dez. 2011.

SOUZA, Marcelo Lopes de. "Território" da divergência (e da confusão): em torno das imprecisas de um conceito fundamental. In: SAQUET, M. A.; SPOSITO, E. S. Território e territorialidades: teorias, processos e conflitos. São Paulo: Expressão Popular, 2009. 